Positive Train Control (PTC): Calculating Benefits and Costs of a New Railroad Control Technology Author(s): Randolph R. Resor, Michael E. Smith, and Pradeep K. Patel

Source: Journal of the Transportation Research Forum, Vol. 44, No. 2 (Summer 2005), pp. 77-98

Published by: Transportation Research Forum

Stable URL: http://www.trforum.org/journal

The Transportation Research Forum, founded in 1958, is an independent, nonprofit organization of transportation professionals who conduct, use, and benefit from research. Its purpose is to provide an impartial meeting ground for carriers, shippers, government officials, consultants, university researchers, suppliers, and others seeking exchange of information and ideas related to both passenger and freight transportation. More information on the Transportation Research Forum can be found on the Web at www.trforum.org. 


\section{POSITIVE TRAIN CONTROL (PTC): CALCULATING BENEFITS AND COSTS OF A NEW RAILROAD CONTROL TECHNOLOGY}

The purpose of this analysis was to quantify the business benefits of Positive Train Control (PTC) for the Class I freight railroad industry. This report does not address the safety benefits of PTC. These were previously quantified by the Rail Safety Advisory Committee (RSAC), which identified nearly a thousand "PPAs" (PTC-preventable accidents) on U.S. railroads over a 12-year period, and determined the savings to be realized from each avoided accident. The RSAC finding was that avoidance of these PPAs was not, by itself, sufficient (from a strictly economic point of view) to justify an investment in PTC.

Examples of potential business benefits include:

- $\quad$ Line capacity enhancement

- Improved service reliability

- Faster over-the-road running times

- More efficient use of cars and locomotives (made possible by real-time location information)

- $\quad$ Reduction in locomotive failures (due to availability of real-time diagnostics)

- Larger "windows" (periods during which no trains operate and maintenance workers can safely occupy the track) for track maintenance (made possible by real-time location information)

- Fuel savings

This paper presents the results of the analysis. It is important to recognize, however, that the state of the art in making these estimates is not sufficiently mature to make exact answers feasible. Presented here are the best estimates now possible, with observations as to how better information may be developed. Benefits were estimated in the above areas and the cost of deploying PTC on the Class I network (99,000 route miles and 20,000 locomotives) were calculated. The conclusions of the analysis were as follows:

- Deployment of PTC on the Class I railroad network (99,000 route miles, 20,000 locomotives) would cost between $\$ 2.3$ billion and $\$ 4.4$ billion over five years

- Annual benefits, once the system was fully implemented, were estimated at \$2.2 billion to $\$ 3.8$ billion

- Internal rate of return was estimated (depending on timing and cost) to be between $44 \%$ and $160 \%$

\section{by Randolph R. Resor, Michael E. Smith and Pradeep K. Patel}

\section{INTRODUCTION}

The purpose of this analysis is to quantify the business benefits of Positive Train Control (PTC) for the Class I freight railroad industry. ${ }^{1}$ Positive Train Control can include many different capabilities, covering a range of railroad functions. Through use of a digital data link and real-time train location information, PTC can be a train control system, with the digital data link and the on-board computer (OBC) used for issuance and enforcement of movement authorities. $^{2}$ The data link may also be used to transmit work instructions to train crews, receive acknowledgment of completed work, or transmit locomotive diagnostic information in real time.

The safety benefits of PTC were previously quantified by the Rail Safety Advisory Committee (RSAC), ${ }^{3}$ which identified nearly a thousand "PPAs" (PTC-preventable accidents) 
on U.S. railroads during a 12-year period, and determined the savings to be realized from each avoided accident. The RSAC finding was that avoidance of these PPAs was not, by itself, sufficient (from a strictly economic point of view) to justify an investment in PTC.

The Congress of the United States then directed the Federal Railroad Administration (FRA) to conduct a separate evaluation of the business benefits of PTC. These are the savings railroads (and shippers) might expect to see if PTC is deployed on the U.S. railroad network. Examples of potential business benefits include:

- Line capacity enhancement

- Improved service reliability

- Faster over-the-road running times

- More efficient use of cars and locomotives (made possible by real-time location information)

- Reduction in locomotive failures (due to availability of real-time diagnostics)

- Larger "windows" (periods during which no trains operate and maintenance workers can safely occupy the track) for track maintenance (made possible by real-time location information)

- Fuel savings

This paper describes the estimation of these business benefits.

\section{Definition of Positive Train Control}

Any PTC installation will consist of three distinct segments:

- The vehicle segment: on-board computer (OBC), location system, digital data link

- The wayside segment: wayside interface units for defect detectors, signals, and track switches; radio towers

- The central office segment: central computers, dispatcher interface

This analysis quantifies benefits for a stand-alone "vital"4 system, which includes OBC, digital data link, and a central safety system. The PTC system evaluated here is based on the North American Joint PTC project in Illinois, which supplements differential GPS ${ }^{5}$ with accelerometers and a gyroscope that give locomotives the ability to resolve location down to a particular track. This location accuracy enables
PTC to support "moving block" operation, in which the distance between following trains is reduced to that required to stop the following train short of a rear-end collision. ${ }^{6}$

\section{QUANTIFICATION OF BENEFITS}

The benefits of PTC are realized in a number of ways. Line capacity and service reliability are improved by the availability of accurate, real time data on train location and speed. This enables train dispatchers to respond more quickly to service disruptions, and to more quickly formulate alternative dispatching plans as circumstances change.

Moving block (or dynamic block) permits trains to follow more closely, increasing line capacity. Faster over-the-road running times result from better "meets" dispatchers know train position more accurately and trains can follow more closely).

PTC also provides the capability to issue instructions (work orders) to train crews in real time. These instructions direct crews to deliver or pick up freight cars. PTC also permits the crews to report the completion of this work in real time. This permits more effective management of rail equipment.

The digital data link in PTC can be used to report diagnostic data on locomotives in real time, allowing shop personnel to diagnose malfunctions and order necessary parts before a locomotive arrives in the shop. Diagnostics also should provide warning of impending failures, possibly allowing train crews to take actions that avoid an en-route failure that delays trains.

Real-time data on train location and speed also will allow track maintenance forces (track inspectors and others) to more effectively utilize their time. Traffic density on the U.S. rail network has increased significantly since deregulation of the industry in 1980 (Association of American Railroads, 2004). This has made the scheduling of track time for inspection and maintenance more and more difficult. Real-time, accurate information on train location should permit an increase in the productivity of track forces, although this benefit is not quantified here.

Finally, real-time position information will allow train dispatchers to pace trains between scheduled meet points, permitting fuel savings. 
Current practice is to run trains at maximum authorized speeds, often arriving at meet points well ahead of schedule. With real-time information on the location of opposing trains, it may be possible to slow a train down to save fuel.

Note that some of these benefits might be obtained by other means. For example, some railroads are now using handheld wireless devices for work order reporting. Use of computer tools to develop more efficient operating plans might produce increases in equipment utilization similar to those achievable with PTC. Some improvements in locomotive performance have already been obtained by use of on-board diagnostics. One Class I railroad is experimenting with an on-board computer that attempts to minimize fuel consumption subject to various schedule constraints.

The largest benefit categories are:

- A reduction in equipment ownership cost, because of an estimated 5\% to $10 \%$ increase in car velocity

- The avoidance of a large investment railroads would otherwise have to make to increase capacity on an estimated 8,300 route miles of railroad (about $8 \%$ of the network) currently operating at or above design capacity. Here, the cost of constructing the 8,300 miles of track has been annualized over a presumed 80 year life at a discount rate of $7 \%$; to this cost has been added an annual cost to maintain 8,000 additional miles of mainline track.

- Significant benefits to shippers from a presumed improvement in service quality

Other benefits are relatively much smaller.

Expected costs of PTC have also been quantified. Available information from railroads and suppliers has been used to estimate the costs of the three segments of PTC. Of these, the cost of the central dispatch office is the least certain. In earlier analyses for Canadian National Railways and Burlington Northern Railroad, the cost of the central office equipment was estimated to be about the same as that of the wayside and vehicle components of the system. However, in this analysis, central office cost is estimated to be a relatively smaller part of the total, for two reasons. First, in the past decade most of the Class I railroads have built consolidated dispatching centers, and will most likely put PTC equipment in these existing buildings (previous studies assumed the need to build new dispatching centers). Second, control office software is now being developed at test installations on railroads. By the time any decision is made to install PTC nationwide, the necessary software should already have been developed. It will only require customization for each railroad installation. But because of the uncertainty over central office cost, a very large range has been used.

Most of the benefits identified here are savings to the railroads from more efficient operation. In the case of line capacity, the annual amounts shown are an annualization of the capital cost of 8,300 miles of second main track, plus the annual cost of maintaining that track. Car and locomotive savings are similarly calculated. In each case, an annual ownership cost is calculated using a purchase price, an expected service life, and a cost of money.

It is important to note that it is by no means certain that railroads will realize all of the benefits estimated here. Railroads might choose to give some of the savings to their customers in the form of lower rail rates. Historically, $80 \%$ of the savings railroads have realized since deregulation have been given to shippers (Martland, 1998). But whether the benefits flow to railroads or to their customers, in one way or another the entire U.S. economy benefits.

\section{SPECIFIC AREAS OF BENEFIT}

\section{Line Capacity}

Real-time location information allows railroads to operate with dynamic, rather than fixed-length blocks between trains. Functionally, dynamic headways ${ }^{8}$ in PTC work as follows:

- The OBC on each train continuously calculates a minimum safe stopping distance

- Using this distance, the central safety system can calculate a minimum safe distance between opposing and following trains

- This minimum distance is constantly recalculated by the OBC and the central dispatching software 
Dynamic headways can potentially increase line capacity by permitting shorter and lighter trains to operate on closer headways, rather than constraining all trains to the separation required by the longest and heaviest trains. The potential savings due to avoided investment in additional track and right-of-way (ROW) has been quantified here. Dynamic headways can also, in conjunction with a local tactical planner, reduce average running times. For instance, a $20 \%$ reduction in run time means that a train that used to take five hours for a trip will now take four hours. This provides an extra hour when the track is free to run another train. Any reduction in run time produces an equal increase in track availability.

The amount of capacity expansion which might be needed, and hence the total cost of capacity expansion, depend on a number of factors which are difficult to estimate. Line capacity is determined by a number of location- and routespecific factors, including grades and curvature, operating speeds, type of signal control, and traffic mix. The specific actions that must be taken to resolve capacity bottlenecks will also differ from location to location.

In this analysis, an attempt has been made to determine the route mileage of the Class I railroad network that is now operating at or above capacity. This mileage has, in turn, been used to estimate the cost of needed capacity additions, a cost that may be avoided by PTC installation.

Lines Currently at Capacity. The Volpe Rail Network (VRN) contains data on annual traffic volume in millions of gross tons (MGT), type of signal control, number of trains per day, and number of main tracks for each line segment. To determine the capacity of a given segment, the network was divided into four categories, by current type of signal control (Armstrong, 1979):

- "Dark" (unsignaled)

- Automatic block signals (ABS)

- Centralized traffic control (CTC)

- Double Track CTC

About half the 99,000 route miles of Class I track is dark, with trains dispatched by voice radio. ABS track typically also uses voice radio, with the signals providing protection against following trains. CTC is the current state of the art in train control, although first deployed in 1927 (The Unofficial Toledo \& Ohio Central Home Page, 2004). In CTC territory, trains move on signal indication, and double track CTC permits movement on either track in either direction under signal control.

ZETA-TECH previously calculated a practical maximum line capacity for each of these types of signal systems Resor, Smith and Patel, 1997). This was done by using data on type of signal control, operating speed, number of trains, and frequency and severity of train delays to construct a scalar number called dispatching effectiveness for each of a number of line segments. The study used actual train movement data and minimum train running times (developed through use of computer simulation) for 33 Class I line segments to develop statistical estimates of the effectiveness of operation of railroad line. Dispatching effectiveness could range from 0.0 to 1.0 ; in practice, the lowest effectiveness was about 0.35 , the highest about 0.8 . Examination of the results of the analysis of the 33 line segments allowed conclusions to be drawn regarding the traffic levels at which specific segments were beyond their practical capacity. From these observations, the thresholds in Table 1 were developed. Specific segments where traffic exceeded these thresholds for current signal systems were then identified using the Volpe model, and a total mileage for the segments in each category was calculated. To estimate the cost of increasing capacity, a set of rules was developed for adding line capacity in the most cost-effective manner. If traffic on a dark segment exceeded capacity, the most effective remedy was the addition of block signals. On ABS lines, the signals were upgraded to CTC. On CTC lines, a second track was added. On double-track CTC, a third main track was added.

It must be emphasized that the track mileage in Table 1 is on lines already operating at or above capacity. These lines are experiencing poor performance, which causes train delays and loss of equipment productivity. Installation of PTC will provide an immediate benefit. While it is true that additional capacity may be required later as traffic grows, installation of PTC will 
resolve operating difficulties that already exist. The benefit is thus the potential for PTC to permit railroads to defer expenditures they would otherwise have to make to expand capacity.

Cost of Increasing Capacity. Railroads can increase network capacity either by improving the signal system or by adding track. Control system enhancements are certainly less costly than adding track. An industry signal expert provided rough estimates of the cost of upgrading signal systems shown in the last column of Table 2. ${ }^{9}$ Obviously, a railroad will select the least costly alternative for increasing capacity. In dark and ABS territory, this will mean adding ABS or CTC (at the appropriate cost per mile). For single- or double-track CTC, the signal system is already state of the art. The only way to increase capacity further, without use of some new control technology (such as PTC), is to add additional main track. Construction cost for new track is about $\$ 1,000,000$ per mile, plus $\$ 15,000$ per mile for signals.

Of course, PTC also offers a capacity increase, and is certainly less costly than additional main track. However, absent the installation of PTC, railroads will have no option but to add main tracks as traffic continues to increase. Table 2 shows the total one-time capital cost of adding this track.

A more useful number might be the annualized cost of these 8,394 miles of track. There are two components to this cost: the annualized cost of the track construction, figured at $\$ 1,015,000$ per mile, and the annual cost to maintain the track. The annualized construction cost is based

Table 1: Criteria for Capacity Improvements

\begin{tabular}{|l|c|c|c|c|}
\hline \multicolumn{1}{|c|}{$\begin{array}{c}\text { Type of Signal } \\
\text { Control }\end{array}$} & $\begin{array}{c}\text { Capacity } \\
\text { (Annual } \\
\text { MGT) }\end{array}$ & $\begin{array}{c}\text { Track Miles } \\
\text { Above Cap. }\end{array}$ & $\begin{array}{c}\text { Remedy to Increase } \\
\text { Capacity }\end{array}$ & Cost per Mile \\
\hline $\begin{array}{l}\text { Dark territory } \\
\text { (no signals) }\end{array}$ & $15 \mathrm{MGT}$ & 8,697 & Install ABS & $\$ 125,000$ \\
\hline ABS territory & $35 \mathrm{MGT}$ & 1,789 & Install CTC & $\$ 65,000$ \\
\hline CTC single track & $75 \mathrm{MGT}$ & 4,452 & Add double track & $\$ 1,015,000$ \\
\hline CTC double track & $150 \mathrm{MGT}$ & 3,942 & Add additional track & $\$ 1,015,000$ \\
\hline
\end{tabular}

NOTE: CTC capacity enhancement reflects cost of additional track at \$1 million per mile plus cost of CTC signaling on new track at \$15,000 per mile.

Table 2: Estimated One-Time Cost of Enhancing Line Capacity on Segments With Capacity Constraints

\begin{tabular}{|c|c|c|c|c|c|}
\hline $\begin{array}{c}\text { Type of } \\
\text { Signal Control }\end{array}$ & $\begin{array}{l}\text { Miles } \\
\text { Over } \\
\text { Cap. }\end{array}$ & $\begin{array}{c}\text { Capacity } \\
\text { Enhancement }\end{array}$ & $\begin{array}{c}\text { Cost } \\
\text { per Track } \\
\text { Mile }\end{array}$ & $\begin{array}{l}\text { Additional } \\
\text { Signal } \\
\text { Cost per } \\
\text { Mile }\end{array}$ & $\begin{array}{c}\text { Estimated } \\
\text { Cost (millions) }\end{array}$ \\
\hline Single-Track CTC & 4,452 & Track & $\$ 1,000,000$ & $\$ 15,000$ & $\$ 4,519$ \\
\hline Double-Track CTC & 3,942 & Track & $\$ 1,000,000$ & $\$ 15,000$ & $\$ 4,001$ \\
\hline Total & 8,394 & & & Total & $\$ 8,520$ \\
\hline
\end{tabular}


on a life of 80 years $^{10}$ and a discount rate of $7 \%$. The annual maintenance cost is based on the industry average spending per track mile for capital investment plus maintenance of way operating expenses (such things as track inspection, snow removal, and minor maintenance) for all track owned by Class I railroads. Applying these numbers to the 8,394 miles of track produces the totals shown in Table 3 .

It is important to note that the costs in Table 3 are for addressing current, not future, capacity constraints. In the absence of an industry decision to install PTC, even more investment will be required if traffic continues to increase. Projections by the American Association of State Highway and Transportation Officials predict a $57 \%$ increase in freight movement by 2020 (American Association of State Highway and Transportation Officials, 2003). If this increase in demand occurs, then the additional 8,000 miles of track discussed here would be inadequate and even more investment to accommodate additional demand would be required. Investment in PTC would, however, permanently forestall the need for 8,000 additional track-miles of capacity.

\section{Equipment Utilization}

According to a study on dispatching effectiveness in railroading, significant reductions in travel time are available when there is a greater availability of real-time or near real-time information for railroad dispatchers (Resor, Smith and Patel, 1997). Analysis showed that a travel time reduction of $2.3 \%$ could be achieved if dispatchers received train position information every 3.5 minutes, as would be expected under
PTC, rather than every 17 minutes, as would be expected under a classic CTC system.

Railroad business case analyses conducted in the early 1990s identified very significant line capacity increases available from implementation of PTC. These capacity increases were achieved by use of sophisticated meet/pass planning algorithms, combined with the dynamic headways made possible by the PTC train control technology. In Burlington Northern's analysis, a meet/pass planning model developed at the University of Pennsylvania was applied to actual train movement data on $16 \mathrm{BN}$ line segments (Resor and Smith, 1989). In all cases, use of the dispatching model produced substantial improvements in running time. Improvements ranged from less than $10 \%$ for high-priority (intermodal) trains to as much as $35 \%$ for low-priority coal and grain trains on some lanes.

In the present analysis, more modest improvements have been assumed. For intermodal trains (which already enjoy preferential dispatching treatment) a reduction of only $5 \%$ to $10 \%$ in running times has been estimated after accounting for a non-line-haul percentage of $52 \%$, the dock-to-dock reduction in time becomes $2.5 \%$ to $5 \%$. For carload freight service, where cars must pass through multiple yards, some of the reduction in over-the-road running time will be lost during yard visits, producing only a modest $2.5 \%$ to $8.5 \%$ reduction in dock-to-dock average time.

For bulk commodity movements (coal and grain) the potential benefit appears much larger, since these trains are not generally yarded between origin and destination. A reduction of between $6 \%$ and $15 \%$ in terminal-to-terminal

Table 3: Annualized Cost of Additional Track to Address Line Segments Already at or Above Capacity

\begin{tabular}{|l|r|r|r|r|}
\hline $\begin{array}{c}\text { Type of } \\
\text { Signal Control }\end{array}$ & $\begin{array}{c}\text { Miles } \\
\text { Over Cap. }\end{array}$ & $\begin{array}{c}\text { Total } \\
\text { Annualized Cost } \\
\text { (millions) }\end{array}$ & $\begin{array}{c}\text { Total Annual } \\
\text { Maint. Cost } \\
\text { (millions) }\end{array}$ & $\begin{array}{c}\text { Grand } \\
\text { Total Cost } \\
\text { (millions) }\end{array}$ \\
\hline Single-Track CTC & 4,452 & $\$ 317.7$ & $\$ 269.4$ & $\$ 587.1$ \\
\hline Double-Track CTC & 3,942 & $\$ 281.3$ & $\$ 238.6$ & $\$ 519.9$ \\
\hline & & & & $\mathbf{\$ 5 0 8 . 0}$ \\
\hline Total & $\mathbf{8 , 3 9 4}$ & $\mathbf{\$ 5 9 9 . 0}$ & & $\mathbf{\$ 1 0 7 . 0}$ \\
\hline
\end{tabular}


time has been estimated, based on the $\mathrm{BN}$ analysis and some more recent work.

Table 4 quantifies the benefits of precision dispatching in terms of equipment ownership savings. In each case, the running time improvement identified in the analysis has been discounted by the percentage of time a car is actually moving (which varies between $52 \%$ and $59 \%$ depending on type of traffic).

Some administrative benefits might be realized, in terms of improved and simplified timekeeping and recording of such items as initial and final terminal delay, but these benefits have not been quantified here since they will be location-specific and cannot easily be estimated for the entire Class I railroad network.

Impact of Yards. What about the yards? Is it not the case that any gain in line-haul running times will simply be lost in additional time to traverse the yard? While it is true that time required to switch trains is a very significant part of the travel time of any railroad car, it is most emphatically not the case that gains in the line-haul would simply be erased in the yards. In fact, more predictable running time for the line haul will make yard operations easier, because yard employees will have better information on the expected arrival times of trains and can thus plan operations more effectively. This may lead to reduced time in yards. This is amply demonstrated in the literature (Martland and Smith, 1989).

\section{Work Order Reporting}

The purpose of the work order system is to plan and schedule the work of train crews. However, it is not possible to schedule all work in advance, because it is impossible to perfectly predict future occurrences. However, the addition of unplanned work may mean delays to cars or train crews, since without advance knowledge of work to be done, crews may run out of time before completing all scheduled work and any additional work. ${ }^{11}$ Outbound connections in yards may also be missed if large volumes of additional work delay completion of a switching shift.

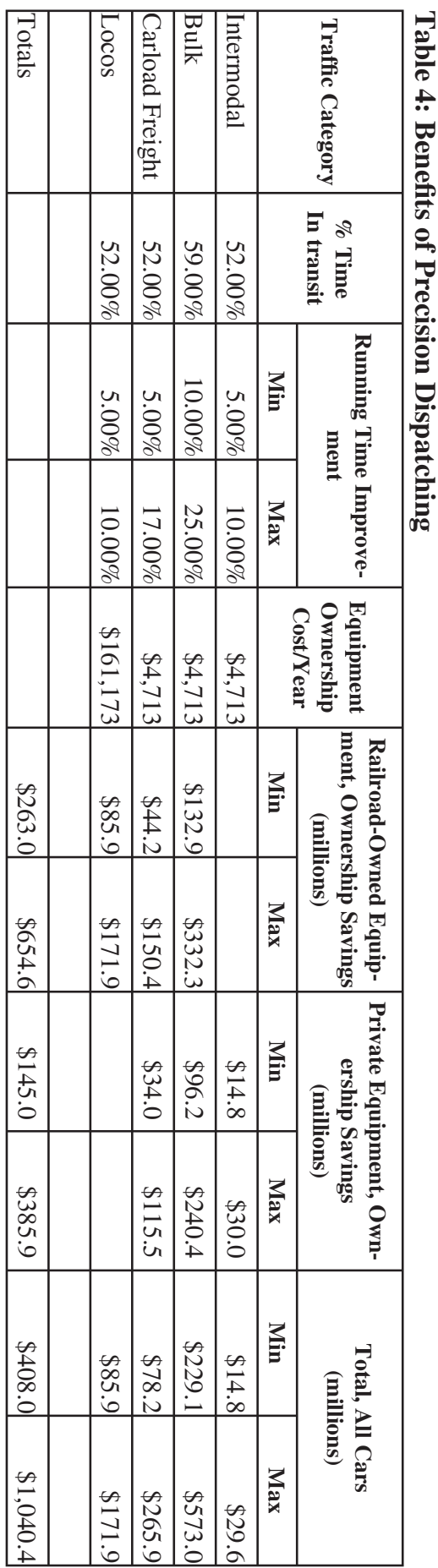


Real-time or near real-time information will reduce additional, unplanned work by reducing the volume of inaccurate or out-ofdate information used in the generation of work orders. Because yard and industry switchers and local freights perform most additional work, the benefits resulting from a reduction in additional work will be realized mostly in these services. For this reason, the analysis presented here is confined to switchers and local freights.

Real-time transmission of train crew work instructions and reports of work completed may be expected to produce the following benefits:

1. A $5 \%$ improvement in inbound schedule adherence for all carload freight, based on an estimated $4.5 \%$ reduction in average yard time.

2. More timely response to customer "pull" requests (not quantified in this analysis due to a lack of specific data)

3. A reduction of one day's transit time for $7.5 \%$ of carload freight outbound from shipper to yard, due to ability to pre-block cars on local freight trains for onward connections.

4. A reduction of the same percentage $(7.5 \%)$ in cars handled in yards. This benefit has not been quantified in this analysis because yards have not been explicitly modeled.

The benefits of real-time work order reporting apply only to carload freight traffic.

A detailed description of the methodology used to develop the benefits estimates shown in Table 5 may be found in an earlier study (Resor, Smith, and Patel, 1992).

\section{Locomotive Diagnostics}

Locomotive diagnostics are sensors that monitor critical locomotive components (air intakes, fuel injectors, electrical system) and provide warnings to train crews and/or mechanical maintenance employees when components are close to failure. Most modern diesel locomotives are equipped by manufacturers with diagnostic systems of varying complexity and sophistication. Therefore, the central question in this part of the analysis is whether real-time transmission of this diagnostic information to a central location adds significant value. The analysis presented here assumes the existence of a digital data link (installed for train control purposes), and an onboard computer. In this case, the incremental cost of locomotive monitoring with real-time reporting is small.

Because of data limitations, this analysis addresses only reductions in en-route failures (and resulting delays) and reductions in maintenance hours required (with a consequent reduction in time off line per locomotive). An annual savings was generated in each of these areas by using available data such as annual expenditures for maintenance, the ownership cost of locomotives (a level annuity based on purchase price), and a cost per train delay (based on the ownership cost of cars and locomotives on a typical train).

To quantify the magnitude of potential benefits, a simulation model was developed by Burlington Northern to estimate the reduction in work hours required to diagnose locomotive

Table 5: Estimated Annual Savings from Use of Real-Time Work Order Reporting

\begin{tabular}{|l|r|r|r|r|}
\hline \multicolumn{2}{|c|}{ Carloads 2002 } & $\begin{array}{c}\text { \% Saving } \\
\text { One Day }\end{array}$ & $\begin{array}{c}\text { Cost/Car } \\
\text { Day }\end{array}$ & $\begin{array}{c}\text { Total Annual Sav- } \\
\text { ings (millions) }\end{array}$ \\
\hline Inbound & $6,260,000$ & $5 \%$ & $\$ 12.92$ & $\$ 4.0$ \\
\hline Outbound & $6,260,000$ & $7.5 \%$ & $\$ 12.92$ & $\$ 6.1$ \\
\hline Total Carloads & $12,520,000$ & & & $\$ 10.1$ \\
\hline
\end{tabular}


problems. This estimate was then used in a model developed by Northrop Corporation to estimate total labor savings. To apply the Northrop model, fleet performance statistics (frequency of failures) are needed. This data was obtained from two Class I railroads for 2003.

It was calculated that availability of realtime diagnostic information could save $8.3 \%$ of total labor in a base case in which no locomotives had diagnostic equipment. In fact, since 1987 railroads have been purchasing new locomotives equipped with factory-installed diagnostics. The BN simulations indicated that on-board diagnostics with no real-time transmission capability could achieve $44 \%$ of the reduction in hours estimated for on-board diagnostics with real-time transmission of diagnostic data to the repair shop. This means that for those units already equipped with diagnostics, only $44 \%$ of the $8.3 \%$ savings can be taken.

A review of locomotive purchases by major North American railroads for the years 1987 - 2001 (Association of American Railroads, 2004) indicates that 9,730 of the 2001 fleet of 19,745 units have been purchased or rebuilt since 1985 . Therefore the $8.3 \%$ savings in labor hours applies only to the $50.7 \%$ of locomotives in service that were built prior to 1985 . For the remaining $49.3 \%$, the benefit is reduced by $44 \%$ $* 8.3 \%$, to a savings of $4.6 \%$.

Total estimated benefits from use of realtime locomotive diagnostics are shown in Table 6 . The estimated savings for locomotives without diagnostics is $\$ 469.7$ million *.507*.083, or $\$ 19.8$ million annually. For locomotives with diagnostics, annual savings is $\$ 469.7$ million * $.493 * .038$, or $\$ 8.8$ million.

\section{Fuel Savings}

Previous studies by Burlington Northern Railroad and Canadian National Railways examined in detail the potential for fuel savings through use of Positive Train Control. These savings had two sources:

- The use of an "energy management system" (EMS) to minimize fuel consumption within the constraint of a defined schedule by optimizing each train's velocity profile.

- The use of a "pacing" algorithm in the computer-aided dispatching system to supply target arrival times at meet points to trains, allowing them to operate at less than track speed where doing so would meet the arrival target, thereby saving fuel.

Both $\mathrm{CN}$ and $\mathrm{BN}$ developed estimates of fuel savings in the range of $2.5 \%$ due to pacing and more efficient dispatching. A great deal of effort was expended in simulations of operations in order to develop these numbers, and they represent the best available estimates of savings from PTC implementation (Resor, Smith, Patel and Kondapalli, 1990).

In the quantification of benefits, it was decided to use a range rather than a point estimate for most sources of benefits. A range of $1.5 \%$ to $3.5 \%$ was selected for quantifying fuel savings. For the entire U.S. railroad industry, fuel represented an annual expense of some $\$ 3.791$ billion in 2001 (AAR, 2004). Thus a

Table 6: Estimated Annual Savings, Real-Time Locomotive Diagnostics

\begin{tabular}{|c|c|c|c|c|c|c|}
\hline Loco Fleet & $\begin{array}{c}\text { Avoided } \\
\text { Failures }\end{array}$ & $\begin{array}{c}\text { Failures per } \\
\text { Loco* }\end{array}$ & $\begin{array}{c}\text { Failures per } \\
\text { year }\end{array}$ & $\begin{array}{c}\text { Avoided } \\
\text { Failures }\end{array}$ & Cost/Failure & $\begin{array}{c}\text { Avoided Cost } \\
\text { (millions) }\end{array}$ \\
\hline 20,506 & $50.0 \%$ & 2.5 & 51,265 & 25,633 & $\$ 1,350$ & $\$ 34.6$ \\
\hline
\end{tabular}

*Failure frequency calculated from 2003 data for two Class I railroads

\begin{tabular}{|c|c|c|c|c|c|c|}
\hline Loco Fleet & Diagnostics & $\begin{array}{c}\text { No } \\
\text { Diagnostics }\end{array}$ & $\begin{array}{c}\text { Total Annual Labor } \\
\text { Cost, Loco Maint. } \\
\text { (millions) }\end{array}$ & $\begin{array}{c}\text { Savings, Locos } \\
\text { without Diagnostics } \\
\text { (millions) }\end{array}$ & $\begin{array}{c}\text { Savings, Locos } \\
\text { with Diagnostics } \\
\text { (millions) }\end{array}$ & $\begin{array}{c}\text { Total Savings } \\
\text { (millions) }\end{array}$ \\
\hline & $49.3 \%$ & $50.7 \%$ & & $8.3 \%$ & $3.8 \%$ & \\
\hline 20,506 & 10,109 & 10,397 & $\$ 469.7$ & $\$ 19.8$ & $\$ 8.8$ & $\$ 28.6$ \\
\hline
\end{tabular}


$1.5 \%$ to $3.5 \%$ savings produced a range of $\$ 57$ million to $\$ 133$ million in fuel cost savings.

\section{SHIPPER BENEFITS}

What is the value of better service? Benefits to the shipper as a result of PTC implementation by railroads can be estimated by measuring the reduction in shippers' logistics cost. The most important of these logistics benefits is associated with the ability of railroads to provide improved on-time service. Here are three methods by which shipper benefits from PTC implementation may be measured:

1. Inventory reduction cost method - Determine the savings shippers might realize in terms of the reduced inventory portion of logistics cost if service reliability improves.

2. Price elasticity method - Determine what additional amount shippers might be willing to pay for improved service reliability.

3. Logistics cost elasticity method - Determine benefits based on the cross-elasticity of demand and price relative to PTC-enabled improvements in transit time and its variability.

These methods do not all measure precisely the same thing. The first method only investigates the inventory portion of logistics cost, both the size of safety stock and the value of in-transit inventory. The second looks at how much shippers are willing to pay for better service; and the third gives a measure of total logistics cost based on theoretical studies. Because the ability to measure the value of improved service with great precision does not yet exist, these techniques are merely presented as different ways of getting an estimate of potential benefits and assessing their size. In addition, analysis of the information here will assist in understanding where emphasis should be placed on improving the accuracy with which such phenomena can be measured.

There seems to be little question that PTC can improve service reliability. The issue here is one of quantifying the magnitude of improvements. These benefits are first quantified in terms of potential service improvements. These im- provements can be inferred from a Harvard Business School Case Study (Harvard Business School, 1991) as follows:

- For improvement in percent of carload shipments arriving on time: $3.5 \%$

- For the percent improvement in travel time variance: $7 \%$

The analytic steps involved in the analysis needed to translate these service improvements into dollar benefits may be understood through close examination of Table 7. Frequent reference to this table will be made in the next few pages while describing the computational steps involved. As the computational techniques involved in these three methods are complex, the columns in Table 7 have been numbered. This will assist in describing how each computation proceeds.

\section{Method 1 - Calculating Benefit From Inventory Cost Reductions}

One technique for determining the benefits of improved service reliability is to look at potential changes in "safety stock," the goods carried in inventory to protect against service failures. As the rise of "just in time" inventory systems indicates, a reduction in inventory is a real saving for the shipper. So rather than examining the effect of improved service on elements of the logistics chain, the effect is quantified in terms of reduction in safety stock inventory for the shipper and receiver.

Every shipper must arrange to have raw materials, work-in-process, and finished goods at the right place at the right time. When a customer places an order, the shipper will compete best if that product is available right away and in the right condition. Being out of stock can be enormously expensive. The actual transportation of the shipper's goods by the carrier is only one element in a series of activities associated with the total logistics process.

Many authorities may be consulted regarding the logistics costs associated with shipping (Cook et. al, 1999). However, a more general approach is provided by Cass Information Systems. Each year, the company produces a report on the state of logistics in the United States (Cass Information Systems, Inc., 2003). The Cass re- 
port provides, among other elements of data, transportation costs, inventory carrying costs, and administrative costs.

From the point of view of service reliability, the shipper's benefit will come from holding less inventory. The more unreliable the delivery time of a shipment, the larger the amount of safety stock that must be held. Inventory carrying costs consist of interest on the capital associated with investment in the product perishability and obsolescence, insurance, taxes, and storage costs. The total of these costs, by Cass' estimate, would be about $21 \%$ of the total value of inventory for 2002. However, this estimate is based partly on an interest cost of only $1.5 \%$. Research on the long-term cost of equity capital reveals that it is about $6 \%$ to $7 \%$ (Reilly, 1979). Using $6 \%$ to $7 \%$ rather than $1.5 \%$ as a cost of capital increases total carrying costs to about $26 \%$ of the value of inventory.

The method used in this report divided shipments into categories based on two-digit Standard Transportation Commodity Codes (STCCs). Columns $1-6$ of Table 7 provide the tonnage and revenue information for two-digit STCC groups that represent over $98 \%$ of the tons shipped via railroad.

Columns 3 and 5 show for each STCC group the total number of tons of that group that the railroads shipped in 2002, along with an estimate of the average value per ton of commodities in that group. For an estimate of the value per ton in each of the STCC groups, this report used data provided in a report prepared by Reebie Associates for the Ohio Department of Transportation (Ohio Department of Transportation, 2002). Because the cited report provides these values for 1998, this report adjusts those values over the intervening years using appropriate producer price indexes from the Bureau of Labor Statistics.

The annual value of goods shipped by rail is shown in column 6 , which is the product of columns 3 and 5. Adding up the values in column 6 shows that a total of approximately \$1.6 trillion. This amount indicates that the railroads are shipping about $16 \%$ of the nation's $\$ 10$ trillion annual GDP.

Column 4 of Table 7 provides the average revenue per ton for goods in each STCC group shipped in 2002.
To determine how greater reliability will impact the shipper, it will be important to know how much inventory shippers must hold for each of these kinds of freight to guard against the variability of transportation service. For the most part, shippers will wish to avoid a stockout situation. To guard against stockout due to slow transportation, a shipper will want to maintain a bit of inventory. The question is how much. In the case of the railroad, that inventory can be estimated by determining the standard deviation of travel time. If the shipper wants to reduce the probability of a stockout because of shipping failure to less than $2 \%$, for example, then a safety stock of two "standard deviations" of days would be sufficient. For example, if the standard deviation in railroad service time were two days, then a stock of four days' worth of product would be sufficient. If, on the other hand, the shipper wants to reduce the probability of stockout because of shipping failure to less than $0.5 \%$, then an inventory containing at least three standard deviations of shipping time would be necessary.

The financial consequences of a stock-out can vary, and so, of course, can the value of avoiding one. The financial consequence of a stock-out will depend on the demand for the product, the value of it, and the cost of transporting it or carrying it in inventory. The amount of inventory kept by a shipper to avoid a stock-out will vary in a manner that depends on these factors. A study by the FHWA makes a judgment as to the optimal probability of stock-out that a shipper should work toward based on all these factors (Federal Highway Administration, 2002). While this amount does vary, a stockout probability of $0.5 \%$ is not out of line.

To perform the analysis, each commodity must be assigned a freight car type. The largest difference in standard deviation of travel time is between intermodal shipments, carload shipments and unit train shipments. STCC 46 (miscellaneous mixed shipments), which is nearly always shipped via intermodal, and STCC 37 (transportation equipment), which receives intermodal-like service, are classified as intermodal. Unit trains are generally used to transport STCCs 10, 11, and 14. All other commodities are considered to be shipped in carload lots (boxcars). 


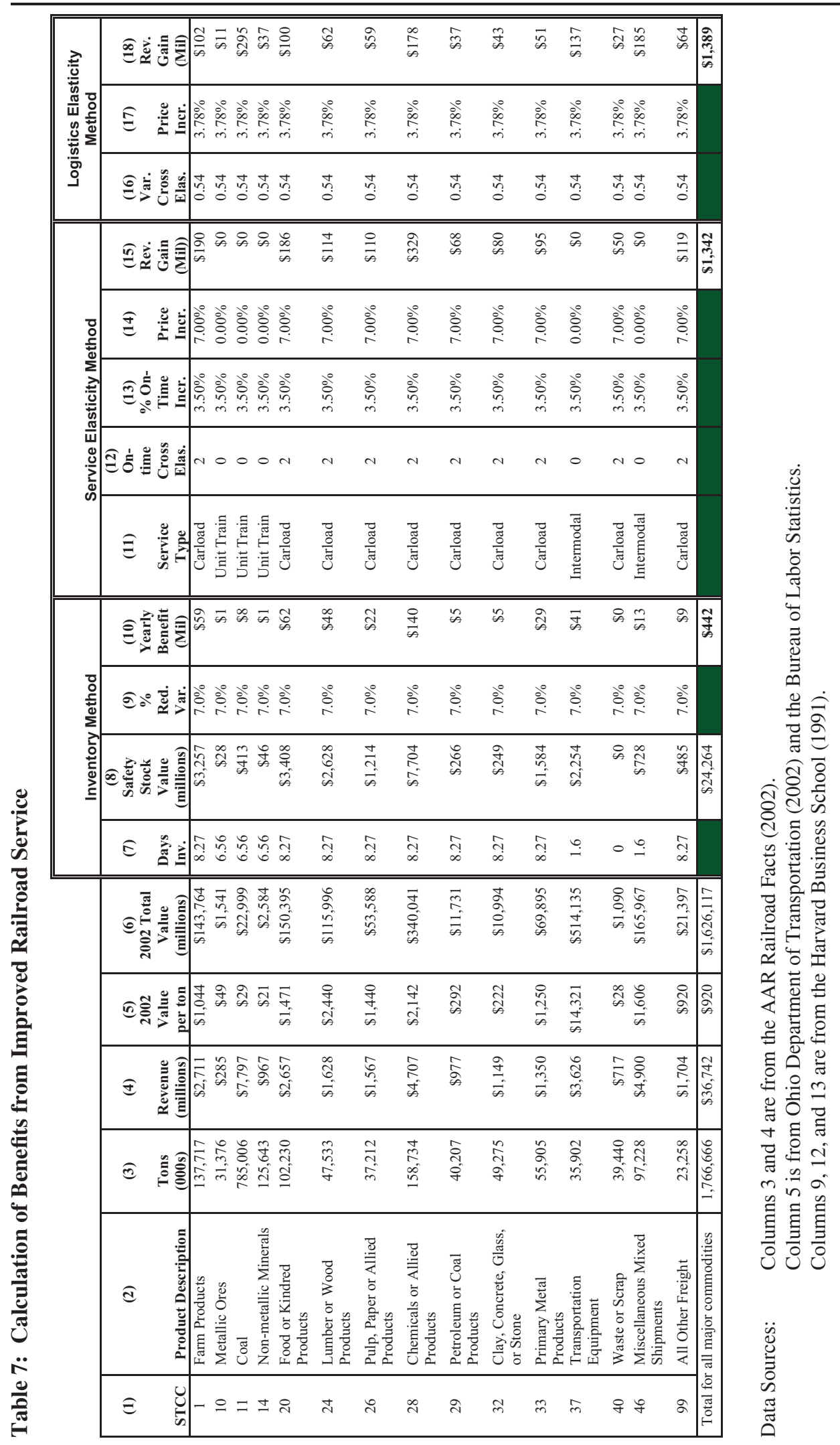


It is now possible to calculate the value of the inventory that is held to guard against variations in rail transit time. This calculation appears in columns $7-10$ of Table 7. For details as to how the computation proceeds in each case, consider the computation for Farm Products (STCC 10). As shown in column 6 , the railroads shipped $\$ 143,746$ million of STCC 10 in 2002. To avoid potential stock out because of the lack of reliability in rail transit times, the shipper must hold 8.27 days worth of safety stock (column 7 - based on the rail standard deviation of 2.62 days). The value of this safety stock is calculated from the total value of product shipped each day (column 6 divided by 365 - daily shipment value) multiplied by 8.27 (column 7) to produce the value of required safety stock, as shown in column 8 . The savings to the shipper is a savings in the carrying cost of this inventory, or the safety stock multiplied by $26 \%$. This number ( $\$ 846.8$ million), not shown in the table, is then multiplied by the percent reduction in standard deviation (column 9) to yield the inventory benefit that is shown in column 10 or $\$ 59$ million. The total annual benefit for all commodities is $\$ 442$ million.

Mean and variance of railroad transit times were found in a very thorough study of the Waybill Sample for 1991 (Kwon, et. al.1995). Table 8 summarizes the findings of this study. From this information, it is possible to develop the amounts of safety stock that shippers will need to guard against stockouts caused by transportation failure. Figures in Table 8 are based on a stockout probability of $0.5 \%$.

There will be one exception to that approach. The only commodity that is not used in any further processing or that does not need to be sold afterward is waste and scrap. There will be no inventory savings estimate made for that commodity.

\section{Method 2 - Calculating Benefits Based on Elasticity of Demand}

A second method for calculating the savings from improved rail service is the 'stated preference' method. Unlike a revealed preference analysis, which involves a study of actions actually taken by shippers in response to changing price and service levels, a stated preference method can achieve similar results using a survey.

In 1989, the Burlington Northern Railroad (BN), predecessor to Burlington Northern and Santa Fe Railway (BNSF), completed such a study to determine the revenue potentially available from service improvements resulting from adoption of the Advanced Railroad Electronics System (ARES). ${ }^{12}$ The results of the study were developed into two case studies by Harvard Business School on the potential for ARES (Harvard Business School, 1991). The study looked exclusively at shipment of truck-competitive commodities. The railroad's question was: what levels of service improvement would cause the shipper to consider switching from truck to rail?

The survey instrument used in the BNSF study was based on a definition of reliability that is a bit different from the one used in the inventory method and logistics method for calculating this benefit. For the BNSF study, reliability was defined as the proportion of time that a shipment arrived when the shipper wanted it to arrive. This definition is consistent with the way that a shipper sees reliability. A relationship between this reliability measure and standard deviation will be discussed later.

Table 8: Mean and Standard Deviation of Railroad Transit Times

\begin{tabular}{|l|c|c|}
\hline \multicolumn{1}{|c|}{ Equipment/Service Type } & $\begin{array}{c}\text { Average Travel Time } \\
\text { (Days) }\end{array}$ & $\begin{array}{c}\text { Standard Deviation of Travel Time } \\
\text { (Days) }\end{array}$ \\
\hline Boxcar & 7.19 & 2.62 \\
\hline Unit Hopper Car & 5.25 & 2.04 \\
\hline Double-stack Container Car & 2.53 & 0.5 \\
\hline
\end{tabular}


The results of the survey indicated that for $1 \%$ increase in transit time reliability, the railroad could expect a revenue increase of $4 \%$. This is a very large number. This result implies that if the railroad can improve its on-time service by just two or three percentage points (that is, about $3 \%$ to $4 \%$ better than it is now), the incremental revenue could be as much as $12 \%$ to $16 \%$ (when keeping the quantity shipped constant). While these gains would apply only to carload freight, the service elasticity still seemed quite high.

It is for this reason that executives at the Burlington Northern were highly skeptical of the price/service elasticity estimates developed from the survey. As reported in the Harvard Business School Case Study, BNSF managers' own estimates of price elasticity with respect to service ranged from zero to 0.4 . In response to the need to move forward with a study on ARES, they compromised on a value of 2.0. The pool of available benefits using this compromise value for elasticity is used for computation in Table 7.

The calculation of benefits using this technique proceeds in columns $11-15$ in Table 7. A description of the calculation procedure for farm products follows. Column 11 indicates that farm products receive carload style service. Column 12 shows the cross elasticity of price with respect to on-time service, which for carload-style service is 2.0. Column 13 shows the increase in on-time performance capability that PTC can generate, which is reported in the Harvard Business School Case Study as $3.5 \%$. Multiplying this service improvement by the elasticity number indicates that a price improvement of $7 \%$ can be expected. This price improvement is then multiplied by the revenue generated by farm products (column 4) to produce the estimated increase in railroad revenue shown in column $15, \$ 190$ million (0.07 $*$ \$2,711 million).

The total annual shippers' benefit from PTC, using this calculation method, is $\$ 1.3$ billion.

\section{Method 3 - Logistics Analysis}

A check on the value of service is available from a draft government document on the effect of freight on the U.S. economy (Federal Highway
Administration, 2002). That draft document contains a chart showing the elasticity of transportation demand with respect to price as well as the elasticity with respect to "transit time and transit time variability." The latter elasticity does not distinguish between transit time and its variance. Because evidence exists that customers are more concerned about transit time variance than about transit time itself, use of this elasticity would be conservative in the sense that actual elasticity is likely to be larger (Harvard Business School, 1991). Further, the study focuses primarily on motor carrier transportation, which is already reliable to an extreme degree; therefore, variability in reliability itself may not be sufficient to observe the sensitivity to reliability that customers actually show.

The report indicates that elasticity of demand with respect to own price is -0.97 and that elasticity of demand with respect to transit time and its variability is -0.52 . Combining these yields a cross elasticity of -0.54 , which will be used to determine the price gain available from improved service.

As reported earlier, a reduction of $7 \%$ can be expected in transit time with PTC-style improvements. Applying a cross-elasticity of -0.54 to the entire $\$ 36$ billion annual railroad market yields an increase of $\$ 1.4$ billion annually in price for a $7 \%$ transit time and variability improvement. When applied to carload freight only, the price improvement would be limited to $\$ 700$ million annually (because carload freight accounts for about half of railroad revenue).

\section{Total Annual Shipper Benefits}

In addition to benefiting from improved service, shippers will have the added advantage of lower cost transportation through an increased use of lower-priced rail service. Rather than calculate that amount here, we elect to round the result in Table 7 upward, yielding a maximum annual benefit of approximately $\$ 1.4$ billion (Method 2). As a low estimate, we select a number between the inventory gain of approximately $\$ 400$ million annually and the high estimate of $\$ 1.4$ billion annually, that is, $\$ 900$ million.

As mentioned earlier, the shipper category of benefits has generated more controversy than 
any other. There are at least two reasons for this:

1. The benefit, if it exists, is very difficult to measure.

2. The benefit may not accrue to the railroad. Each is discussed in turn.

Measurement difficulties are apparent in all three of the methods used here. The inventory method is easiest to understand. However, it is well known that there are many other elements of logistics cost, for example the cost of a shipper's production apparatus based on whether JIT logistics is workable. The third method of measuring benefits considers all the elements of logistics cost; however, it is exceptionally complicated and can suffer from problems associated with excessive aggregation. Finally, the second method (elasticity) has the virtue of simplicity because it is based on asking shippers, "How much would you pay?" But it suffers from the problems associated with too much aggregation and too little understanding of the causes for the amounts that shippers say they would pay.

Even if consensus can be reached as to the best way to measure how the system would react in an economic sense to changes in service, there would still be considerable consternation over how to measure service itself. For example, rail carload service is measured in terms of plus or minus one day, while motor carrier service is measured in plus or minus two-hour windows. Will an improvement in service merely raise the bar of expectations as opposed to changing economic behavior?
In addition to trouble posed by the difficulty of measuring shipper benefits is the concern over whether these benefits can be reaped by the railroads themselves. And there is ample evidence that this may not be the case at all. Since deregulation in 1980, railroad costs have plummeted. A recent study (Martland, 1998) indicates that the railroads have simply given about $80 \%$ of that benefit to the shipper.

This paper presents information gathered as the result of a contract with the Federal Railroad Administration. As an agency of the government, the FRA is not concerned whether any identified benefit would accrue to a particular party, only that the benefit exists.

\section{COSTS OF POSITIVE TRAIN CONTROL}

The following tables recap the cost of each of the three segments (vehicle, wayside, central office) of PTC. Costs are for equipping the entire Class I network and all locomotives. Costs have been obtained from manufacturers and railroads. They are expressed as ranges, because there remains some uncertainty over what the price of each component might be in an industry-wide deployment.

The FRA study defined two types of PTC; "PTC A," an overlay system, and "PTC B," a fully functional system incorporating dynamic block capability. Costs here are for the more expensive PTC B.

The central office cost remains the greatest unknown. Because much of the work to write

Table 9: Cost per Segment, PTCB (2001 dollars)

\begin{tabular}{|c|c|r|r|}
\hline Segment & Unit & \multicolumn{2}{|c|}{ Estimated Cost Per Unit } \\
\hline & & Low & \multicolumn{1}{c|}{ High } \\
\hline Vehicle & Each & $\$ 30,000$ & $\$ 75,000$ \\
\hline Wayside & Track Mile & $\$ 16,000$ & $\$ 24,000$ \\
\hline Central Office & Each & $\$ 100$ million & $\$ 500$ million \\
\hline
\end{tabular}


vital code has been done as part of the Illinois project, and could presumably be modified at relatively low cost for use in other installations, the "low" cost is probably most appropriate for any single railroad. However, it is doubtful that railroads will choose to share control centers, so the total cost for all seven Class I railroads could conceivably approach the "high" cost.

Total estimated cost is shown in Table 10.

These costs may be overstated, because some investments in PTC-compatible equipment have already been made. Union Pacific Railroad reports that 2,600 of its 6,847 locomotives, or $38 \%$, are equipped with ATCS radios. About $25 \%$ of UP route miles $(9,600$ route miles) are covered by ATCS UHF repeaters.

BNSF reports that about 1,900 route miles are covered by ATCS-type radio, used for switch and signal control. CSX Transportation has about 3,000 route miles of radio coverage, also used for switch and signal control. Whether this equipment might need to be replaced or upgraded to be compatible with a full PTC installation is not known at this time.

Note that the costs in Table 10 are capital costs only. In addition to these costs, an annual charge equal to $15 \%$ of the total capital cost of PTC would be added to operating expenses once PTC is fully implemented. This charge, set at a typical level for the electronics industry, is intended to cover training, maintenance, and technological obsolescence. ${ }^{13}$

\section{SUMMARY OF BENEFITS AND COST/ BENEFIT ANALYSIS}

\section{Summary of Benefits}

Table 11 provides a summary of benefits for PTC. Most of the benefits quantified in Table 11 are savings to the railroads from more efficient operation. In the case of line capacity, the annual amounts shown are an annualization of the capital cost of 8,300 miles of second main track plus the annual cost of maintaining that track. Car and locomotive savings are similarly calculated. In each case, an annual ownership cost is calculated using a purchase price, an expected service life, and a cost of money.

The only benefits that are not direct savings to railroads are the shipper benefits, which are composed of savings shippers might realize in total logistics cost if railroad service improved and rates did not increase.

It is important to note that it is by no means certain that railroads will realize all of the savings in Table 11. Railroads might choose to give some of the savings to their customers in the form of lower rail rates; historically, $80 \%$ of the savings railroads have realized since deregulation have been given to shippers (Martland, 1998). But whether the benefits flow to railroads or to their customers, in one way or another the entire U.S. economy benefits.

Table 10: Total Estimated Cost, PTC B, Class I Railroad Network (2001 dollars)

\begin{tabular}{|l|r|r|r|r|r|}
\hline \multicolumn{2}{|c|}{ Segment } & \multicolumn{1}{c|}{ PTC B Low } & \multicolumn{1}{c|}{ PTC B High } & \multicolumn{1}{c|}{ System Cost (millions) } \\
\hline & & & & \multicolumn{1}{c|}{ Low } & \multicolumn{1}{c|}{ High } \\
\hline Locomotives & 20,506 & $\$ 30,000$ & $\$ 75,000$ & $\$ 615.2$ & $\$ 1,538.0$ \\
\hline Route Miles & 99,250 & $\$ 16,000$ & $\$ 24,000$ & $\$ 1,588.0$ & $\$ 2,382.0$ \\
\hline Central Office & & & $\$ 100.0$ & $\$ 500.0$ \\
\hline & & & & \\
\hline Total PTC cost & & & $\$ 2,303.2$ & $\$ 4,420.0$ \\
\hline
\end{tabular}


Table 11: Summary of Estimated Annual PTC Benefits (all costs in 2001 dollars)

\begin{tabular}{|l|l|r|r|}
\hline \multicolumn{1}{|c|}{ BENEFIT AREA } & & \multicolumn{1}{c|}{ Low } & \multicolumn{1}{c|}{ High } \\
\hline Line Capacity & Avoided Investment & $\$ 299.5$ & $\$ 422.0$ \\
\hline & Avoided Maintenance & $\$ 508.0$ & $\$ 762.0$ \\
\hline Precision Dispatch & Car Ownership & $\$ 322.1$ & $\$ 868.2$ \\
\hline & Locomotive Ownership & $\$ 85.9$ & $\$ 171.9$ \\
\hline Work Order Report & Car Ownership & $\$ 10.1$ & $\$ 10.1$ \\
\hline Locomotive Diagnostics & Locomotive Maintenance & $\$ 28.6$ & $\$ 28.6$ \\
\hline & Locomotive Road Failure & $\$ 34.6$ & $\$ 34.6$ \\
\hline Fuel & & $\$ 55.9$ & $\$ 130.5$ \\
\hline Shipper Benefits & & $\$ 900.0$ & $\$ 1,400.0$ \\
\hline & & & \\
\hline Total Estimated Annual Benefits & & $\mathbf{\$ 2 , 2 4 4 . 7}$ & $\mathbf{\$ 3 , 8 2 7 . 9}$ \\
\hline
\end{tabular}

\section{Costs, Cash Flows, and IRR Calculations}

Table 12 displays estimates of the cost of PTC. These are the total one-time costs of implementing the three segments of PTC: wayside, on-board, and central office. Because of uncertainties, a range is given.

Of course PTC cannot be deployed all at once, and there will be maintenance and training costs as well. Therefore, a cash flow analysis for an investment in both PTC A and PTC B has been carried out using the following assumptions:

- A five-year installation period for the wayside component of PTC, with $20 \%$ of Class I mileage equipped each year

- A five-year installation period for the vehicle component

- A five-year installation and testing period for the central office hardware and software
- A benefits phase-in over a five-year period lagging the installation by one year

- Beginning in Year 6, a charge of $15 \%$ of the total installation cost per year is made for training, maintenance, and obsolescence ${ }^{14}$

- A 7\% cost of money

- A 20-year benefits period

A calculation of internal rate of return (IRR) and cash flow is shown in Table 13, for four scenarios:

- Low cost, high benefits

- High cost, high benefits

- Low cost, low benefits

- High cost, low benefits

To make the IRR calculations, a table of cash flows was prepared, showing net cash flows per year, positive and negative, during the life of the proposed investment. In all cases, the period of negative cash flow is five years or less, and

Table 12: Summary of PTC Costs

\begin{tabular}{|c|c|c|}
\hline \multirow{2}{*}{ Segment } & \multicolumn{2}{|c|}{ Estimated Capital Cost } \\
\hline & Low & High \\
\hline Vehicles & $\$ 615.2$ & $\$ 1,538.0$ \\
\hline Wayside & $\$ 1,588.0$ & $\$ 2,382.0$ \\
\hline Central & $\$ 100.0$ & $\$ 500.0$ \\
\hline Total & $\$ 2,303.2$ & $\$ 4,420.0$ \\
\hline
\end{tabular}


Table 13: Calculated Internal Rates of Return, PTC Four

Analysis Cases

\begin{tabular}{|c|c|c|}
\hline & Low Benefits & High Benefits \\
\hline Low Costs & $95 \%$ & $160 \%$ \\
\hline High Costs & $44 \%$ & $79 \%$ \\
\hline
\end{tabular}

in some cases is less than two years. Cash flow then becomes positive, and stays positive, for the remaining life of the investment. This occurs despite the $15 \%$ annual charge for training, maintenance, and obsolescence.

\section{CONCLUSION}

PTC is a large investment by any measure. A cost of $\$ 2.3$ billion to $\$ 4.4$ billion might seem daunting to an industry with gross revenues of only $\$ 35$ billion. However, the projected annual benefits of $\$ 2.2$ billion to $\$ 3.8$ billion provides a rapid payback period. It should be noted that the value of accident avoidance (the near elimination of human factors accidents) has not been included in either benefit calculation, but is being calculated separately by the Federal Railroad Administration.

Clearly, PTC offers an opportunity to U.S. freight railroads. Implementation of such a system would:

- Improve service reliability for shippers, producing a large benefit for them

- Increase the capacity of about 8,000 route miles that are now at or above capacity, enabling railroads to avoid a very substantial near-term investment in track and signals

- Produce immediate savings in car and locomotive ownership cost through improved utilization

Railroads have been reluctant to invest in this new technology, in part because of capital constraints, in part because of uncertainty about the benefits, and in part through a fear of government action to require the investment on a safety basis. However, PTC does appear to provide significant business benefits to the freight railroads, as well as unquestioned safety benefits through positive enforcement of movement authorities. There remains uncertainty regarding the percentage of benefits railroads might actually realize, as opposed to shippers (in the form of lower rates). Given that there is a stated public policy objective of putting more freight on railroads, possibly there might be some consideration of public financing because the results of this analysis suggest that the benefit to the U.S. economy as a whole (whichever stakeholder received benefits) could be substantial. 


\section{Endnotes}

1. The Surface Transportation Board classifies railroads as "Class 1" if they exceed an annual revenue threshold -- \$277.7 million in 2003. In that year, there were seven Class 1 railroads, 32 regional railroads (revenues of at least $\$ 40$ million annually but less than the Class I threshold) and 510 local railroads with less than $\$ 40$ million in annual revenues.

2. Movement authorities define the distance a train may safely proceed along a railroad track before encountering another train or some other condition, such as a track switch not lined properly, that prevents further movement.

3. RSAC is a working group composed of representatives from railroads, rail labor, rail industry suppliers, and FRA. Its purpose is to develop safety regulations for the rail industry by reaching a consensus among the various stakeholders.

4. "Vitality" is a term used by railroad signal engineers to describe a system that is "fail safe." "Fail safe" means that any failures will place the system in a safer, rather than a less safe, state. For example, a dark signal (due perhaps to a burned out bulb or power supply failure) must be assumed to be displaying its most restrictive indication.

5. The Global Positioning System (GPS) provides the capability to locate an object in threedimensional space anywhere on or above the Earth's surface, using signals transmitted by satellites in geostationary orbit. Differential GPS improves accuracy by using a ground-based transmitter at a known location to correct inaccuracies in the satellite signals.

6. Conventional signal systems rely on geographic blocks of fixed length. The length of these blocks must always be sufficient to allow the longest and heaviest train to stop safely. Further, because the blocks are of fixed length, time separation between trains lengthens when trains travel at less than "track speed" (maximum allowed speed). Both of these factors reduce capacity, because both distance and time separation between trains can be longer than the minimum necessary to ensure safety.

7. A meet occurs when two trains are traveling toward each other in opposite directions. When the physical plant consists of single track with sidings, one of the trains must pull into a siding while the other proceeds along the main track until it meets and then passes the one in the siding.

8. For safety reasons, a train must remain far enough behind the one ahead of it to be able to stop before a collision would occur. CTC systems work by having signals at the side of the track; as a result, such headways must be "fixed" in length, with that length being constrained by the spacing of the signals. When dynamic positioning information of the trains themselves is available, these headways can be varied, that is, made dynamic, based on the available position information.

9. It is difficult to estimate costs precisely, because they depend on the number of controlled turnouts, the number of sidings, the availability of commercial power, etc. The numbers cited here are used for general budgetary purposes.

10. The American Railway Engineering and Maintenance Association (AREMA) sets engineering standards for railroads; 80 years is the recommended design life for bridges and similar structures.

11. Once a crew has worked 12 continuous on-duty hours, by Federal law they must stop work.

12. ARES was the first PTC-type control system tested by a Class I railroad. 
13. BN used a $10 \%$ additive to cover training, maintenance, and capital replacements for its ARES project. The $15 \%$ is a typical number used for electronics and other products that quickly become obsolete.

14. The $15 \%$ figure is used in the electronics industry. BN, in its business case for ARES, used a figure of $10 \%$ to cover training, maintenance, and replacement of parts. A typical number for less sophisticated equipment (such as rail/highway crossings) is $5 \%$.

\section{References}

American Association of State Highway and Transportation Officials. Freight Rail Bottom Line Report. Washington, D.C., 2003.

Armstrong, John. The Railroad - What It Is, What It Does. Simmons Boardman, Omaha, NE, 1979.

Association of American Railroads. Railroad Facts, 2002 Edition. Washington, D.C., 2002.

Association of American Railroads. Railroad Facts, 2004 Edition. Washington, D.C., 2004.

Cass Information Systems, Inc. "The Case for Reconsideration." $14^{\text {th }}$ Annual State of Logistics Report. National Press Club, Washington, D.C., June 2, 2003.

Cook, Peter D., Sanjay Das, Andreas Aeppli, and Carl Martland. "Key Factors In Road-Rail Mode Choice In India: Applying the Logistics Cost Approach.” P.A. Farrington, H. B. Nembhard, D. T. Sturrock, and G.W. Evans, eds. Proceedings of the 1999 Winter Simulation Conference.

Federal Highway Administration. "Meta-Analysis of Logistics Costs and Transport Demand in Relation to Freight Transportation." Freight Benefit/Cost Study, July 2002.

Harvard Business School. "Burlington Northern: The ARES Decision (A)." HBS Case Number 9-191-122. Cambridge, MA, 1991.

Kwon, Oh Kyong, Carl D. Martland, and Joseph M. Sussman. "Origin-to-Destination Trip Times and Reliability of Rail Freight Services." Transportation Research Record No. 1489, Washington, D.C., 1995.

Martland, Carl D. "Sources of Financial Improvement in the U.S. Railroad Industry, 1966-1995." Proceedings, 39 ${ }^{\text {th }}$ Annual Meeting of the Transportation Research Forum Vol. 1, (1997): 58-86.

Martland, C.D. and M. E. Smith. "Estimating the Impact of Advanced Dispatching Systems on Terminal Performance.” Journal of the Transportation Research Forum 30 (2), (1990): 286-300.

Ohio Department of Transportation. Freight Impacts on Ohio's Roadways, June 2002.

Reilly, Frank K. Investment Analysis and Portfolio Management. Dryden Press, Hinsdale, IL, 1979.

Resor, Randolph R., Michael E. Smith, and Pradeep K. Patel. "Train Dispatching Effectiveness With Respect to Advanced Train Control Systems: Quantification of the Relationship." Transportation Research Record No. 1584, Washington, D.C., 1997. 
Resor, Randolph R. and Michael E. Smith. "The Use of Train Simulation as a Tool to Evaluate the Benefits of The Advanced Railroad Electronics System." Journal of the Transportation Research Forum 29 (1), (1989): 163-168.

Resor, Randolph R., Michael E. Smith, and Pradeep K. Patel. “A Real-Time Work Order Reporting System for Rail Transportation: Benefits and System Requirements." Selected Proceedings of the Sixth World Conference on Transport Research. World Conference on Transport Research Society, Lyon, France, 1992.

Resor, Randolph R., Michael E. Smith, Pradeep K. Patel, and Sunil Kondapalli. "Quantification of Expected Benefits: Meet/Pass Planning and Energy Management Subsystems of the Advanced Railroad Electronics System (ARES)." Journal of the Transportation Research Forum 30 (2), (1990): 301-309.

“The Unofficial Toledo \& Ohio Central Home Page," http://www.members.kconline.com/plank/ tocpred.htm.

\section{Acknowledgements}

The work on which this paper is based has been funded by the Federal Railroad Administration under Contract DTRF-53-01-D-0021, "Costs and Benefits of Positive Train Control Systems and Related Technology." Any opinions, findings, and conclusions or recommendations expressed in this paper are those of the authors, and do not necessarily reflect the views of the Federal Railroad Administration and/or the U.S. Department of Transportation.

Randolph. Resor has 28 years of experience in railroading and rail rapid transit. He started his career as special assistant to William Dempsey, the incoming president of the Association of American Railroads, in 1977. Following work at the U.S. Railway Association and the New York City Transit Authority, in 1987 Mr. Resor joined ZETA-TECH Associates. He is the author of more than 30 published papers covering transportation cost analysis, rail operations, and the use of computers in railroading. He is national treasurer of the Transportation Research Forum, and a member of Transportation Research Board Committee AT010, Freight Transport Economics and Regulation. He has a Bachelor of Arts in history and economics from the University of Chicago, and completed a year of graduate study at Northwestern University's Transportation Center.

Michael Smith is a registered professional engineer with 30 years of experience in a wide variety of transportation activities. He started his career in 1975 as a highway engineer with the Federal Highway Administration. Afterward, the Federal Railroad Administration employed Smith as its national expert for the analysis of benefits and costs of investing in railroad branch lines. He then moved to the Association of American Railroads, using both his business and engineering skills in the role of engineering economist, helping the railroads determine whether investment in new technologies makes business sense. When Burlington Northern Railroad began to develop the Advanced Railroad Electronics System, they hired Smith to create a business case for it. Smith was then employed by several consulting organizations, including Bechtel Civil Company, Reebie Associates and Wilbur Smith Associates, where he managed the development and planning of many private and public transportation investments in railroads, toll highways, and waterways. The Surface Transportation Board now employs Smith to participate in staff assessments of railroad rate cases. He has a bachelor's degree in engineering from Ohio State University and a Master of Business Administration from the University of Maryland. 
Pradeep K. Patel has been with ZETA-TECH for 17 years. During that time, he has been involved in various contracts involving Conrail safety analysis, UP/SDP merger analysis, PTC, and numerous other statistical analyses and studies. He designed the statistical methodology used in quantifying the safety performance on various line segments affected by the Conrail purchase. He developed locomotive failure probabilities for the analysis of locomotive health monitoring for Canadian National Railways, and he provided supporting analysis for both the AAR and the Volpe studies of the economic benefits of positive train control. Mr Patel has an M.S. in industrial engineering, University of Houston, and a B.S. in mechanical engineering from Gujarat University (Ahmedabad, India). 